\title{
NEW DANIELI TOP CHARGING UNIT WITH DANCU DISTRIBUTOR FOR ZAPORIZHSTAL BLAST FURNACE NO. 3*
}

\author{
Ewout Tesselaar ${ }^{1}$ \\ Massimiliano Zampa ${ }^{2}$ \\ Edo Enge ${ }^{\beta}$
}

\begin{abstract}
Blast furnace No. 3 at Zaporizhstal in Zaporozhye is rebuilt in 2016-2017. The Ukrainian company is targeting increased production and availability, mainly through the use of new technology. Zaporizhstal awarded a contract for a new Top Charging Unit to Danieli Corus, after comparing all available technologies. Reliability of the chosen charging device is pivotal, since long outages may be required for maintenance/replacement jobs, which strongly affects the availability of the blast furnace. This article describes the Top Charging Unit including DANCU (Danieli Charging Unit) - a robust hydraulic system. The main focus employed by Danieli and Danieli Corus during the development of this system has been availability and maintainability of equipment. This chute type charging unit has only few major moving parts, none of which is complex or vulnerable. The article also describes the main challenges of the project at Zaporizhstal, such as the use of hot sinter.
\end{abstract}

Keywords: Blast furnace, top charging equipment, maintenance, hot sinter operations.

1 M.Sc. and Product Manager - Blast Furnace Charging Technology, Danieli Corus BV, VelsenNoord, The Netherlands.

2 DECM Director Engineering, Danieli Centro Metallics, Buttrio, Italy.

3 Manager Marketing, Danieli Corus BV, Velsen-Noord, The Netherlands. 


\section{INTRODUCTION}

Ukrainian steelmaker Zaporizhstal has signed a contract for a new top charging unit for their Blast Furnace No. 3 with Danieli Corus. The furnace will be rebuilt in 2017 and Zaporizhstal requires increased production and availability levels for the next campaign. The furnace was initially built in 1947 and the last major reline took place in 2000 . Before the reline project, it was equipped with a double-bell type charging unit. To achieve the required production levels during the next campaign, Zaporizhstal explored the installation of a chute-based charging device. The contract for the Danieli Corus Top Charging Unit with DANCU Gearbox, which is a codevelopment with Danieli Centro Metallics, was awarded after a thorough comparison of all available technologies.

Chute-type charging devices have proven to offer optimum control over the distribution of raw material on the blast furnace stockline. Traditionally, these systems are based on electro-mechanical tilting and rotating operations. Many such devices have been known to be vulnerable. Danieli Corus and Danieli Centro Metallics have developed a new technology with the main objectives of maximum availability and maintainability to accommodate the requirements of modern blast furnace ironmaking operations.

\section{Principles of Blast Furnace Charging Technology}

Many of the fundamental advancements in blast furnace ironmaking during the past decades have been process-based rather than equipment-based. Mature equipment and technology, such as a blast furnace cooling and lining system that allows for long campaigns and substantial process optimization, have allowed for these improvements. One major enabler for process optimization has been the (maximized) ability to deposit raw materials on the stockline in the desired position. Some steel producers have been able to achieve excellent results with traditional double-bell tops, but the advent of chute-based charging has brought the industry another step forward in this respect.

The first generations of chute-based charging devices were single source and the complicated, electro-mechanical design was reported to be vulnerable. Maintenance and replacement jobs time consuming and in some cases even frequent. Especially during the 1990s, development for alternative approaches was initiated. Examples of such alternatives are the five-vaned rotor offered by the Russian company Totem, the nested chute of the No-Bell Top offered by Zimmermann \& Jansen and the device offered by Primetals, which is based on the multi-axial Gimbal pivot principle.

Chute-based charging remains the preferred option among blast furnace operators. Charging strategies have been optimized with this method in mind and the concept is proven. Since around 2000, alternative chute-based devices have been developed by a small number of parties. The main focus of these developments has been the elimination of the vulnerabilities of the existing technology. Baotou Steel (or Baogang) from Baotou, Inner Mongolia has successfully developed an alternative based on the application of hydraulics, a number of units of which have been operated successfully in China since. 
Danieli Corus, in cooperation with Danieli Centro Metallics, have taken another step in the development of chute-based charging devices. Similar to the Chinese design, the Danieli system eliminates the complex electro-mechanical planetary gearbox traditionally used for the tilting operation through the application of hydraulics, but there have been many additional improvements. The units have gained substantially in terms of availability through additional redundancy and the application of "failure free" components and equipment, and a new maintenance concept has been developed.

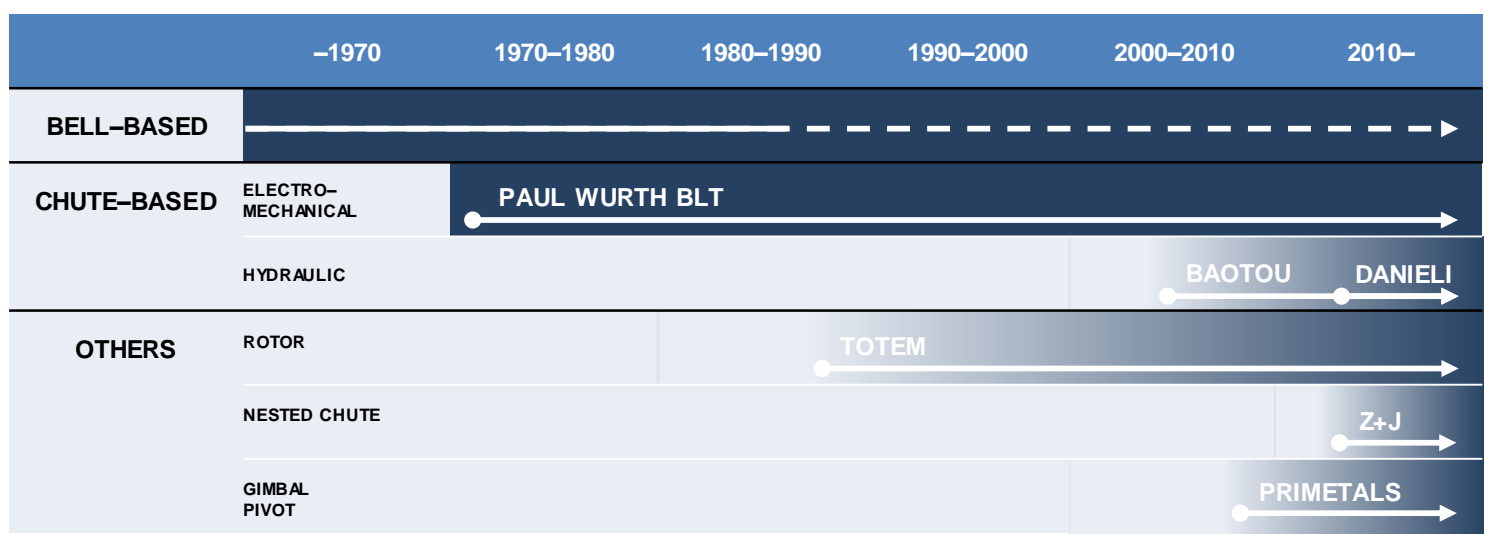

Fig. 1 - Historical overview of blast furnace top charging technologies

\section{THE DANIELI TOP CHARGING UNIT}

\subsection{The DANCU Distributor}

To achieve maximum reliability/availability as well as the most consistent positioning of the chute, hydraulics were selected for most of the core components of the unit. All main components are designed and manufactured to be failure-free and as far as possible redundant. The rotating and tilting movements of the chute are separated, and achieved with a minimum number of moving parts, making this charging unit the most robust design available. For example, hydraulic cylinders located outside the gearbox housing move the outer ring up and down and electric or hydraulic drives rotate the inner ring, which in turn rotates the chute. This straightforward approach eliminates vulnerable and complicated and expensive components such as a planetary gearbox. The main bearing was designed with a maximized seat diameter to eliminate the load inversions experienced with competing designs. The center of gravity of the chute is always within the bearing diameter. The cooling, sealing and refractory designs have also been strongly improved. For uncompromised quality and reliability, manufacturing takes place at the Danieli workshops according to the highest standards. To minimize commissioning efforts on site, all components are submitted to thorough pre-commissioning tests within the workshop premises. 


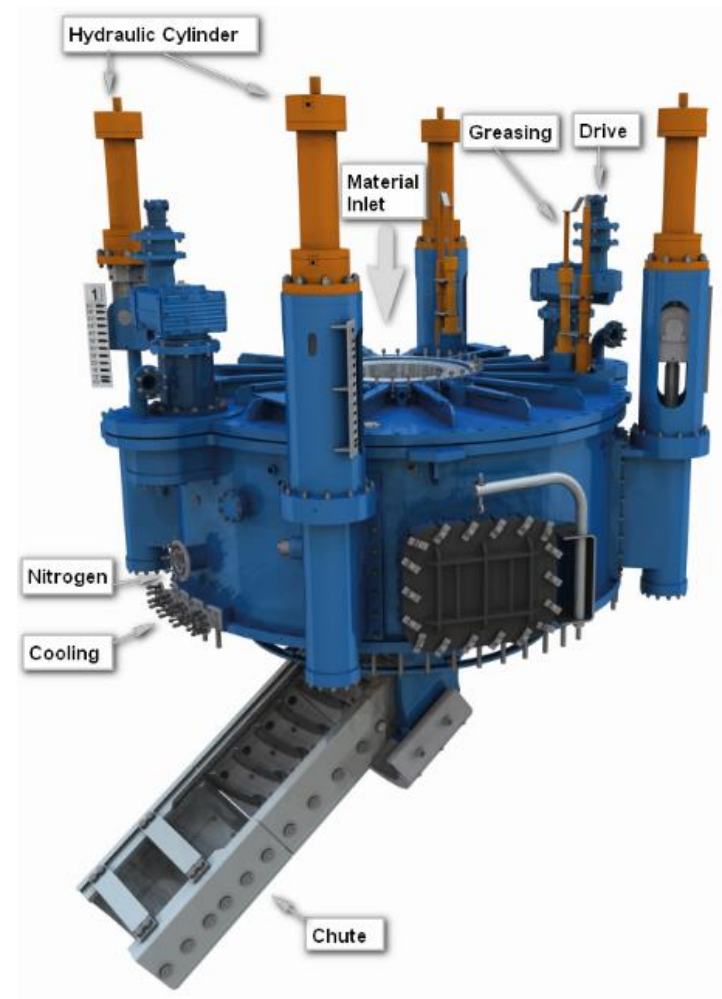

Fig. 2 - DANCU Distributor

The tilting angle is calibrated with simple Temposonic hydraulic positioning devices that offer very accurate control (with a repeatability of $0.02 \mathrm{~mm}$ ). The tilting limits are at $10^{\circ}$ and $63^{\circ}$, which is inherent to the limits of the hydraulic cylinders. The cylinders enable the use of a simple mechanical lock that can be positioned at e.g. $53^{\circ}$. This eliminates the requirement for a complex mechanical lock, which has been a major factor in risk damage with traditional designs. Also, there is no risk of tilt angle drift over time, given the nature of the hydraulic technology applied in the design.

The bottom of the DANCU is cooled with a redundant pressurized circuit with inlet and outlet above the blast furnace lip ring ensuring no fouling of the water. The central part of the DANCU is cooled by a serpentine which removes the heat from the body via a stationary water reservoir. This solution results in simple pressurized supply and return piping even though rotating parts are cooled with high heat transfer coefficients.

\subsection{New Maintenance Concept}

Traditionally, exchange of heavy equipment is time-consuming and often the bottleneck during blast furnace stops. Up to four scheduled maintenance stops per year are typical and the objective is to debottleneck the scheduled activities as far as possible. For the top charging equipment this means that the distributor and large valves, if applicable, need to be replaced within the time required for other blast furnace maintenance such as refractory repairs of the runner system in order to not cause any additional delays. 


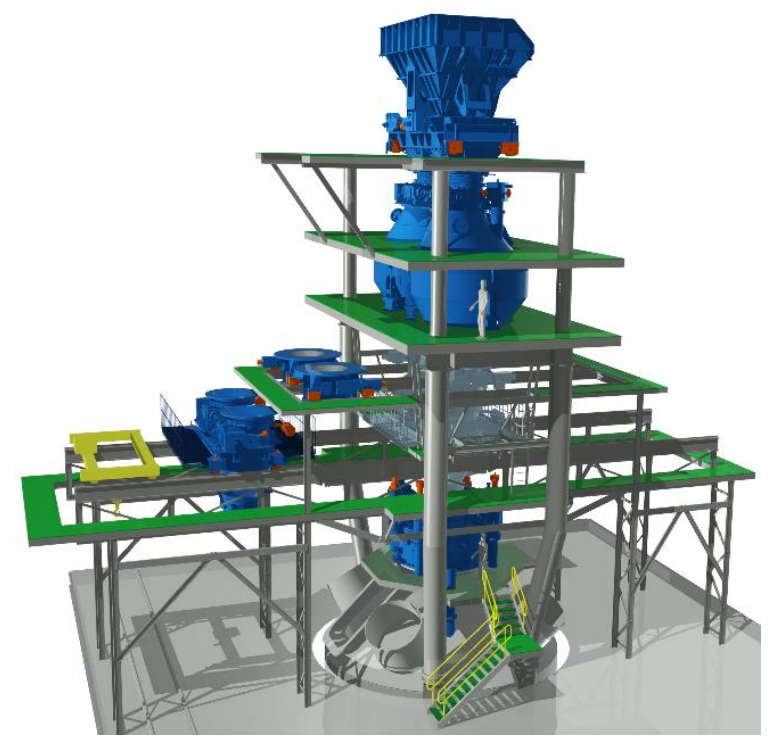

Fig. 3 - General Arrangement of cranes, sliding rails

With the Danieli Corus top charging unit, special cranes are applied and the lay-out is adjusted to improve accessibility through e.g. the application of sliding rail designs for the easiest, safest and quickest replacement of system components. The following main components can be easily removed and re-installed in case of maintenance requirement:

The Receiving Hopper slides in and out

The Upper Seal Valves are hoisted in and out

The Lower Material Gate slides in and out

The Lower Seal Valves and Receiving Funnel slide in and out

The Distributor slides in and out

The Chute is hoisted in and out

The time required for unscheduled maintenance is greatly shortened. For example, the total replacement time of a Lower Material Gate Valve is approximately 7 hours, the total replacement time of a Lower Seal Valve approximately 10 hours and the total time for a maintenance job for the Distributor as little as 26 hours, including the time required to remove it from and return it to its operating position.

However, the main valves and other main equipment are engineered with the same focus on quality and availability as the distributor, making maintenance/replacement requirement highly unlikely. As an example, the lower seal valves:

Are equipped with double bearings, at both sides of the disks

Offer perfect gas tightness via a plan parallel, metal to metal seat and a soft seal Have nitrogen-blasted seat cleaning and steam-heated/cooled valve seats Allow for easy access to the internals

Slide in and out as a module on a sliding rail, also through the application of integrated compensators

Are fully replaceable with the upper seal valves enabling minimization of spare parts 


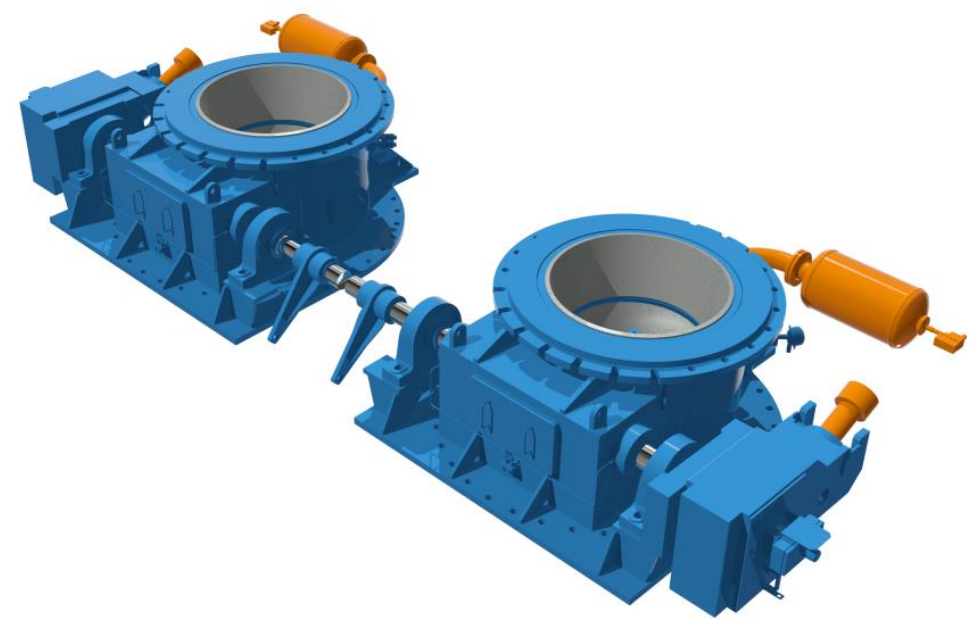

Fig. 4 - Seal Valves

Exchange of the chute requires a maximum of 10 hours. Removing and re-attaching the chute is performed conveniently with a simple, straightforward locking device and a manual tilting drive that is operated from outside the furnace through the manhole of the DANCU distributor. Chute fork replacement is not required given the use of high grade stainless steel and the use of heat protection. The chute's stonebox and remainder wear lining is replaceable in the workshop which further decreases maintenance costs.
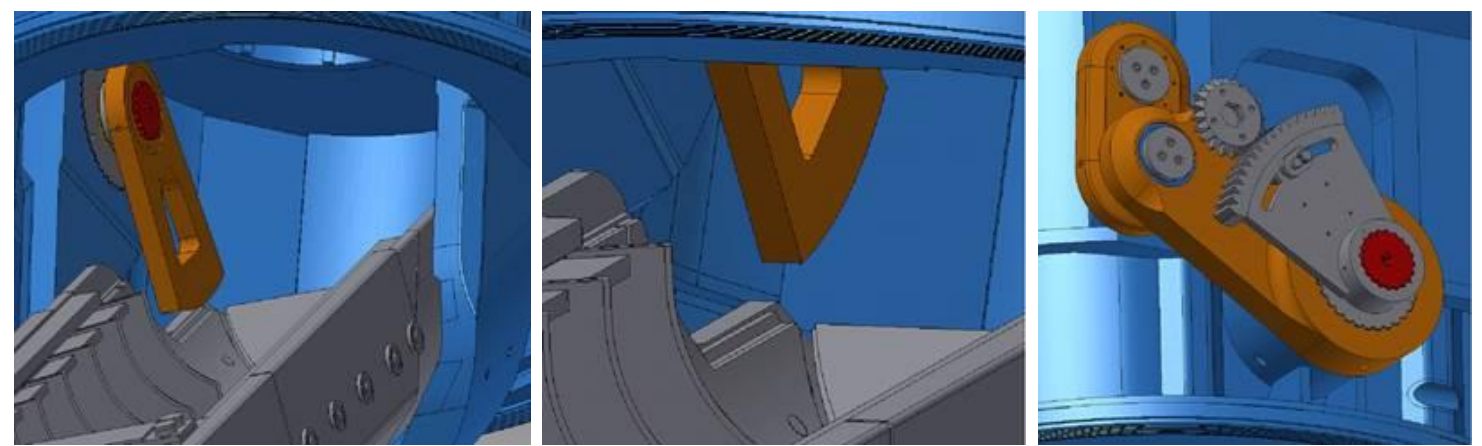

Fig. 5 - Chute locking device in locked, unlocked position and manual tilt drive

The lifetime of moving parts is often determined by the application of sufficient grease. Lubrification is ensured by a fully automated system with sensors indicating the use of sufficient volume per position. No replacement of cartridges is required as all systems are connected to the central supply system. The use of this type of system further minimizes maintenance.

\subsection{Automation and Instrumentation}

A state-of-the-art automation system is vital for successful operation with the top charging equipment. Danieli Corus provides modern Level 1 and Level 2 automation, resulting in low coke operations and fully visualized burdening. A sophisticated conditioning monitoring system enables preventive maintenance. Especially the application of acoustic monitoring for the low speed roller bearings is a state-of-theart development, since traditionally only higher speed bearings would allow for this type of monitoring. Knowing the exact condition of vital components increases the 
system's lifetime since components will not be replaced according to schedule but based on maximized lifespan.

For the purpose of calibration and trimming of the automation system, as well as assess the system's performance, Danieli Corus has developed a new type of digital trajectory probe. After (temporary) removal of the above burden probes, the digital trajectory probe is mounted in this position. It is equipped with impact detection devices that are engineered to match the impact of typical raw materials for blast furnace ironmaking. The devices can be read at a higher frequency than traditional devices, at $1 \mathrm{~ms}$ intervals. The calibration device, which is conveniently installed in a carry-on sized heavy duty case, connects directly to the Top Charging Unit's PLC for direct matching of the logged impact data with the device's operating parameters such as the chute's tilting angle and rotational speed.

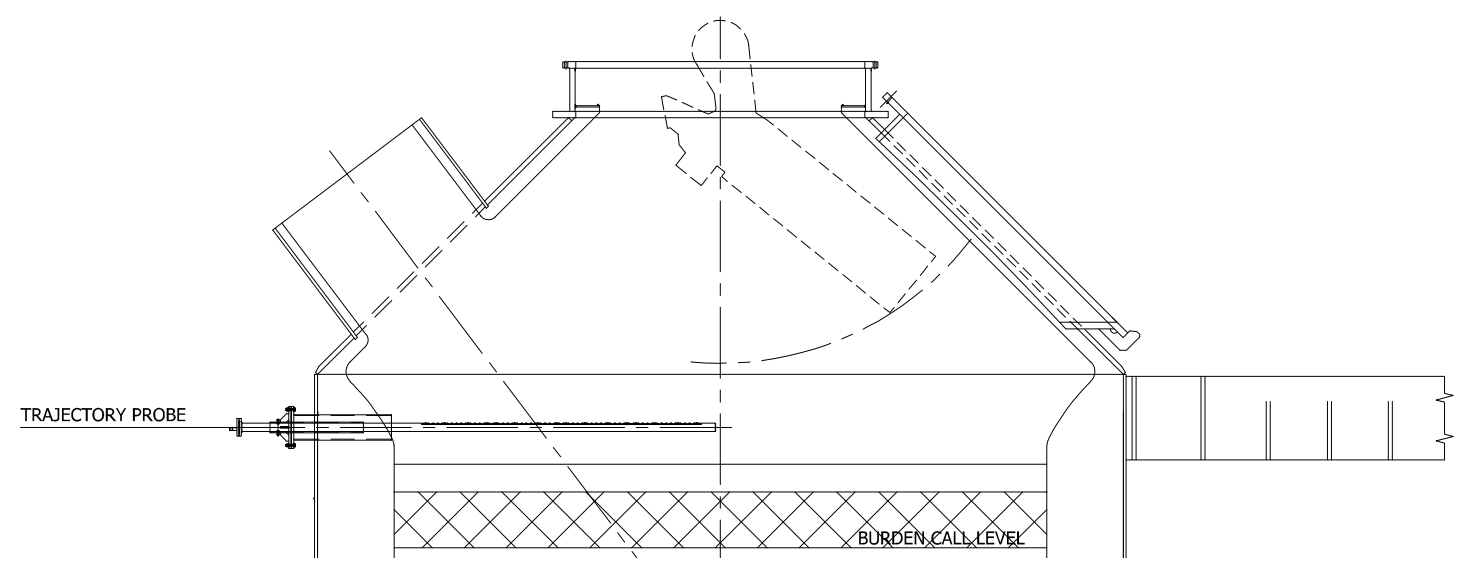

Fig. 6 - Trajectory Probe General Arrangement

\section{APPLICATION AT ZAPORIZHSTAL}

A contract for a Top Charging Unit for the No. 3 blast furnace operated by Zaporizhstal at their plant in Zaporozhye, Ukraine was awarded to Danieli Corus in 2016. Some data about the unit supplied under this contract is summarized in the table below. After fabrication of the distributor, it was submitted to a highly intensive testing procedure at the Buttrio workshop. The unit was installed on a test stand and the hydraulics and electrical equipment were connected as per operational requirements.

Table 1 - Basis of Design

\begin{tabular}{ll}
\hline Receiving Hopper & $27 \mathrm{~m}^{3}$ \\
\hline Material Bins & $2 \times 27 \mathrm{~m}^{3}$ \\
\hline Valves & $0.4 \mathrm{~m}^{3} / \mathrm{s}$ \\
\hline DANCU distributor & Suitable for medium-large \\
& $\mathrm{BF}$ \\
\hline Chute & $3.3 \mathrm{~m}$
\end{tabular}



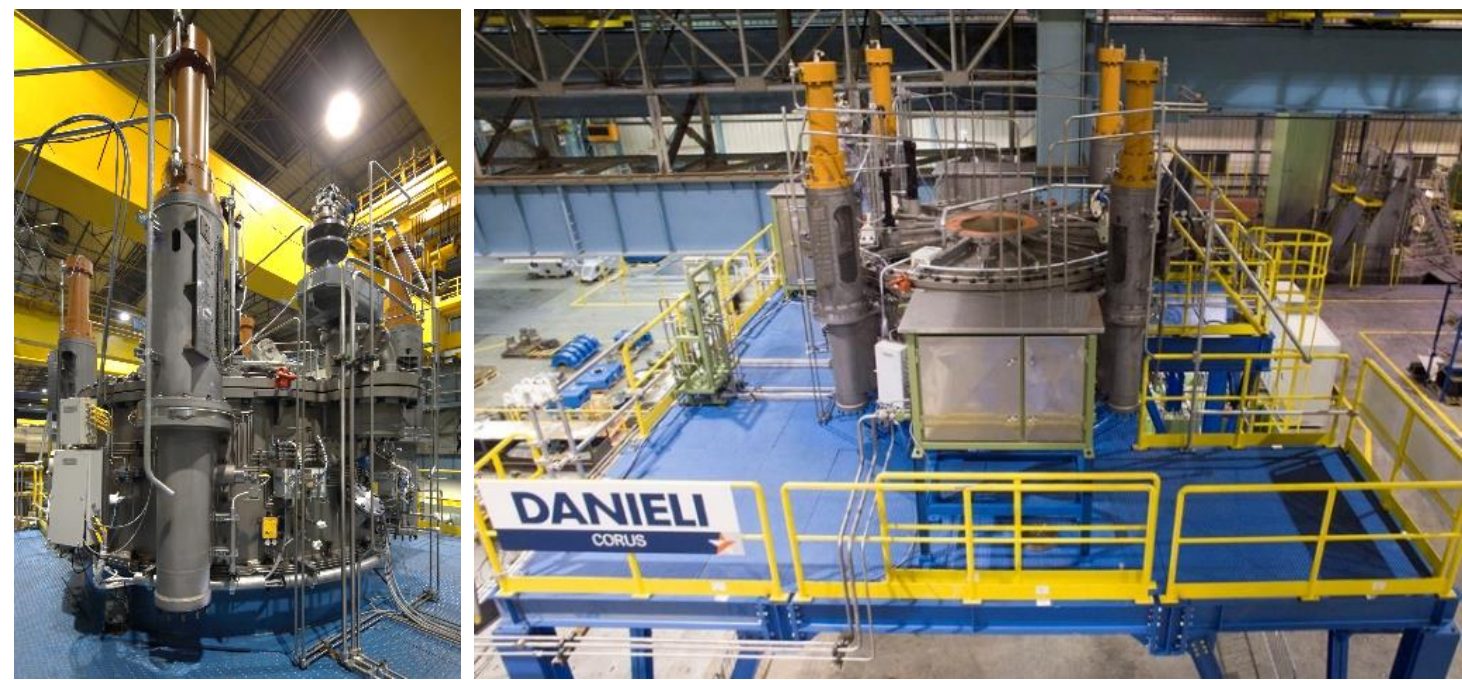

Fig. 7 - DANCU distributor for Zaporizhstal on test stand
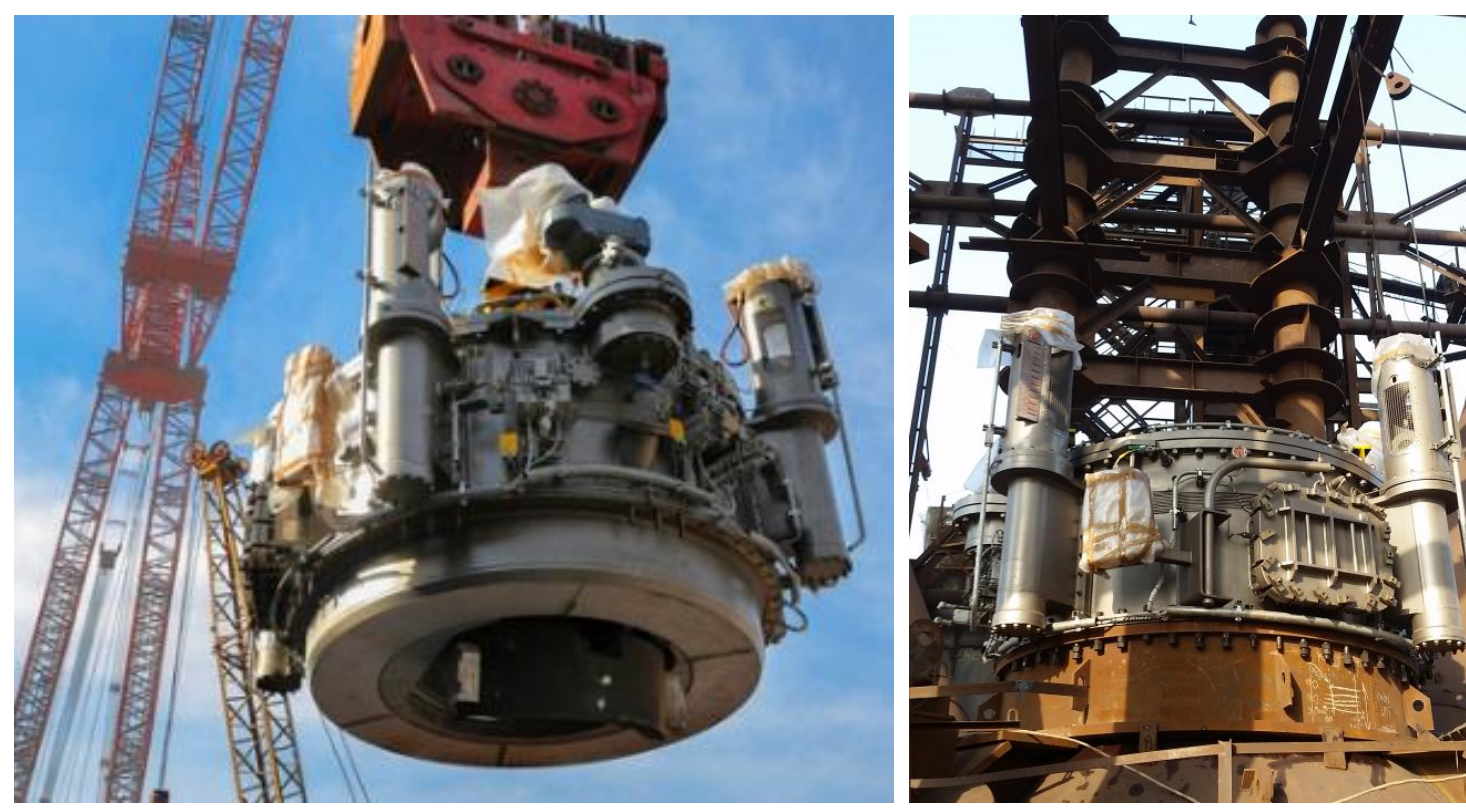

Fig. 8 - DANCU distributor mounted on furnace

After completion of these final tests, equipment was transported to the client's site. The photographs above show the DANCU distributor as it was undergoing these tests as well as in its operating position on top of Blast Furnace No. 3 shortly after arrival at the Zaporozhye steel plant.

\subsection{Ability to Operate on Hot Sinter}

A common operational practice in the Russian and Ukrainian steel industries is the application of hot sinter as raw material for the blast furnace. To accommodate this practice in this cold environment, all major equipment is engineered and manufactured for the ability to accept raw materials with temperatures up to $700{ }^{\circ} \mathrm{C}$ as well as e.g. frozen coke. Valves need to enable pressurization in cycles and charge precisely the required amount to the distributor. Main valves are steamcooled and heated to ensure long lifetime and gas tightness. Special care has been taken for the seals in the valves which differ considerably from traditional designs. 

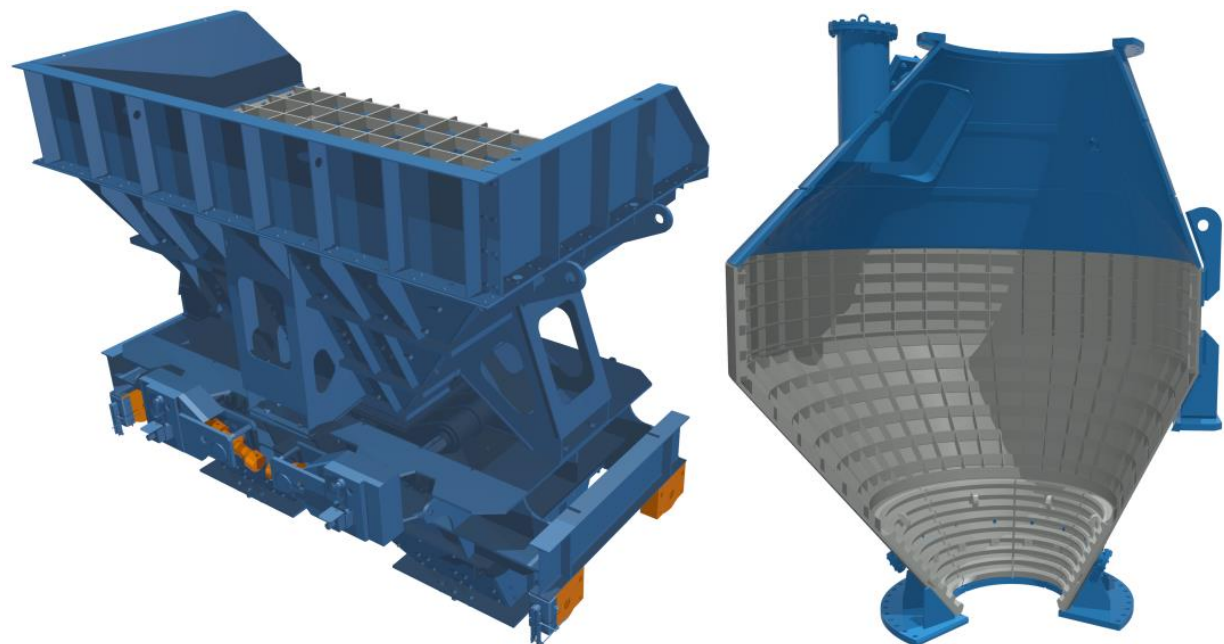

Fig. 9 - Receiving Hopper and Material Bins engineered for temperatures up to $700{ }^{\circ} \mathrm{C}$

\section{CONCLUSION}

Hydraulics are a proven technology with proven long operation times in different fields, including top charging systems for blast furnaces (especially in PR of China); Separating the rotation and tilting operations improve reliability and repeatability while simplifying maintenance by the use of standard components;

The drive items (hydraulic motors and cylinder) are standard components from the market and installed externally with easy access for inspection and maintenance; Redundancy of hydraulic cylinders, drives and other components improves reliability and availability of the total unit;

Whenever equipment requires maintenance or replacement, the new maintenance concept developed by Danieli Corus and Danieli Centro Metallics provides the shortest possible time requirements, allowing for these jobs to be executed during the same time required for other maintenance jobs around the furnace, pre-warnings will indicate when to schedule the maintenance;

The newly developed trajectory probes with direct connection to the Top Charging Unit's automation system allows for optimum calibration and trimming.. 